Document downloaded from:

http://hdl.handle.net/10251/44110

This paper must be cited as:

Boza Garcia, A.; Alemany Díaz, MDM.; Alarcón Valero, F.; Cuenca, L. (2014). A modeldriven DSS architecture for delivery management in collaborative supply chains with lack of homogeneity in products. Production Planning and Control. 25(8):650-661. doi:10.1080/09537287.2013.798085.

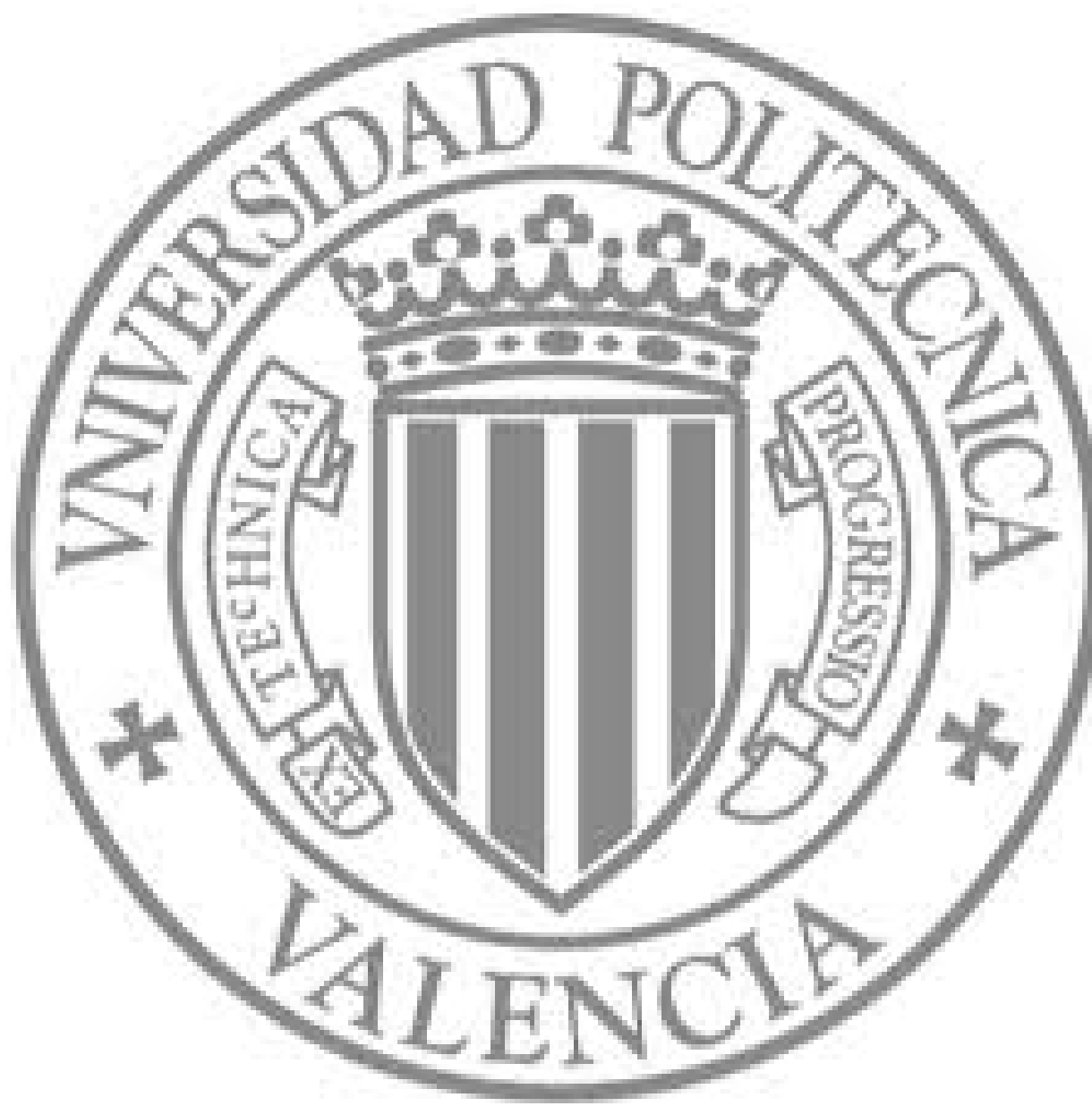

The final publication is available at

http://dx.doi.org/10.1080/09537287.2013.798085

Copyright

Taylor \& Francis (Routledge): STM, Behavioural Science and Public Health Title 


\title{
A model-driven DSS architecture for delivery management in collaborative supply chains with lack of homogeneity in products
}

\author{
Andrés Boza, M.M.E. Alemany, F. Alarcón, Llanos Cuenca \\ Research Centre on Production Management and Engineering (CIGIP), Universitat \\ Politècnica de València. Camino de Vera S/N, 46022, Valencia, Spain.
}

Telf:(34)963877007 Fax (34)963879682

\{aboza, mareva, faualva, 1lcuenca\}@cigip.upv.es

Uniform product deliveries are required in the ceramic, horticulture and leather sectors because customers require product homogeneity to use, present or consume them together. Some industries cannot prevent the Lack of Homogeneity in Products (LHP) in their manufacturing processes, hence they cannot avoid non-uniform finished products arriving at their warehouses and, consequently, fragmentation of their stocks. Therefore, final uniform product amounts do not match planned production ones, which frequently makes serving previous committed orders with homogeneous quantities impossible. This paper proposes a model-driven decision support system (DSS) to help the person in charge of delivery management to reallocate the available real inventory to orders to satisfy homogenous customer requirements in a collaborative supply chain. The DSS has been validated in a ceramic tile collaborative supply chain.

Keywords: decision support system, lack of homogeneity in products, delivery management, collaborative supply chain

\section{Introduction}

Lack of homogeneity in products (LHP) appears in those industries whose productive processes cannot eliminate the heterogeneity of their inputs (i.e., raw material obtained from nature). LHP also appears in the productive processes that introduce some variability into their outputs due to uncontrolled productive factors, even when their inputs are homogeneous (Alemany et al. 2013). LHP may become a considerable problem when customers acquire several units of a given product and require product homogeneity to use, present, arrange or consume them together in order to avoid 
functional or aesthetical problems. A slight difference in a part is easily seen in products such as parquet strips, leatherwear, floor tiles or pearl necklaces (Alarcón et al., 2011).

Companies with LHP cannot foresee the final characteristics of those products in lots defined by the production plan because they cannot prevent non-uniform finished products arriving at their warehouses and, consequently, fragmentation of their inventories. These companies are obliged to include one or several classification stages along the production process. In the classification stage, units of the same product are sorted into homogeneous subgroups (subtypes) based on certain attributes (classification criteria) that depend on each sector where each subtype includes uniform final products. Hence, the products included in each subtype meet customer expectations in terms of functional and/or aesthetics homogeneity. In LHP contexts, customer orders management becomes more complex and therefore the order promising $(\mathrm{OP})$ process plays an important role in this task. The OP process includes the set of business activities that are triggered to provide a response to customer order requests (quantity, delivery date ...). In this process is necessary to compute if there are enough real or planned products available that have not been previously committed (ATP - available to promise).

Traditional ATP assignment systems assume product homogeneity; therefore they allow the accumulation of current uncommitted stocks from warehouses (real ATP) and from planned amounts (planned ATP) of different manufacturing lots and periods. However, companies with LHP obtain non-uniform lots and the real homogeneous quantities remain unknown until production has finished. This aspect becomes a problem when customer orders should be promised based on the planned ATP quantities where real homogenous quantities are not known in advance. This means that, more often than not, 
some ATP-based orders cannot be fulfilled once the production of lots has finished because the amount of available homogeneous product does not suffice. This situation causes problems in committed orders with immediate delivery dates. For such cases, by reallocating the available inventory of each subtype in warehouses (real inventory) among all the orders, it is possible to prioritise those orders with immediate delivery dates.

The decision to reallocate current stock to customer orders becomes complicated in those companies with lots of orders that have different delivery dates and several products in each order (order lines). Furthermore, this situation becomes even more complicated in the LHP context given the fragmentation of inventory because several subtypes of the same product exist and given the homogeneity requirements imposed by the customer. This means having to introduce new constraints when reallocating stock to orders.

Therefore, LHP increases not only the volume of information to be used, but also the number of possible combinations when serving orders, and all of them with different profits. All these factors complicate the task of obtaining solutions that are not just optimum, but also feasible. These additional complexity aspects for reallocating stock justify the use of tools to help with decision making; i.e., mathematical programming models. The solutions obtained with such tools may help the supply chain (SC) minimise the impact of LHP on the customer service level. Hence for the purpose of providing support to delivery management tasks, a model-driven decision support system (DSS) to optimally reallocate the inventory of homogeneous subtypes to LHPcharacterised promised orders in collaborative make-to-stock (MTS) environments is proposed. The model solution provides the orders that can be served with real inventory 
and from which subtype of uniform product they can be delivered, following the maximisation of profits and orders completed with earlier delivery dates.

The rest of the paper is outlined as follows: Section 2 includes a review of the relevant literature relating to the paper. Section 3 describes the developed model-driven DSS for delivery management in collaborative SCs with LHP. Section 4 presents the DSS application to a collaborative ceramic tile SC case. Finally, Section 5 offers the main conclusions and future research lines.

\section{Literature review}

The creation of SCs has offered firms new business opportunities based on collaboration and coordination. Multiple benefits have been identified thanks to collaboration and coordination in SCs (Bititci et al., 2007).

For collaboration to be effective, it is necessary to adapt the distinct SC processes; for instance, the Demand Forecasting process (Poler et al., 2008), the Demand Management process (Abid et al., 2004) or the Reverse Logistic (Hernandez et al., 2010). In the Demand Management domain, the Order Promising Process (Abid et al., 2004) and the ATP allocation are extremely important matters.

In the short term, the customer orders previously committed by ATP allocation should be completed for delivery in order to meet the promised due date. Yet owing to unforeseen events, there may not be enough available stock in the right quantities to cover these orders and to meet the promised due dates. In order to find a satisfactory solution for both customers and SC, some shortage planning models (Pibernik 2006, Zschorn 2006) have been developed. Indeed, shortage planning deals with the activities to be accomplished should stock not be available and includes certain decisions, like customer negotiation (Framiñán and Leisten, 2009), outsourcing (Bhakoo et al., 2012) or substitutive products (Balakrishnan and Geunes, 2000). 
Nonetheless, despite collaboration being important in the order management, very few works have addressed this issue (Alemany et al. 2008, Alarcón et al. 2009), perhaps due to the added complexity that coordination and collaboration entail. This complexity may be further complicated if, besides, the OP Process must consider LHP problems (Alarcón et al., 2011). In such cases, the vast quantity of up-to-date information to be processed, and in real time, plus the swift, reliable requirements involved in replying to customers, render the use of decision-making tools, like DSSs, virtually compulsory.

DSSs can be developed so they can utilise knowledge and handle knowledge sources as effectively as possible (Kubat et al., 2007). One important advantage of DSSs is that the Decision-Maker does not need to understand the complexities of mathematical modelling (Gomes da Silva et al., 2006). The capacity of DSSs to be able to dynamically respond to changes and to communicate with the affected SC nodes could also be stressed, and is a basic requirement for SC collaboration to work (Jagdev and Thoben, 2001) and the technological advances in the Internet make available these collaborative DSS (Boza et al., 2010).

Although relevant research has been done on DSSs in relation to topics such as order planning (Azevedo and Sousa, 2000), order management (Abid et al., 2004) and shortage planning (Okongwu et al., 2012), to our knowledge, there are no works that propose mathematical programming models either in isolation or within the DSS framework, which address reallocating inventories for shortage planning in collaborative contexts with LHP. Thus there is a gap in the literature which justifies the proposal set out in the next section. 


\section{Model-driven DSS architecture for collaborative delivery management in}

\section{SCs with LHP}

This section not only describes the context and problems involved in delivery management in SCs with LHP, but proposes their management within a collaborative framework. Then, it identifies LHP stock reallocation as a solution for shortage situations when delivering orders and proposes a mathematical programming model precisely for this purpose integrated into a DSS.

\subsection{Context: towards a new collaborative framework}

The physical SC configuration is assumed to be composed of three kinds of nodes: several production plants; one central warehouse; several selling points (Figure 1). On the one hand, production plants manufacture in lots following an MTS strategy. All the products may be processed in any production plant and, owing to LHP, each manufactured lot of a given product may give rise to different product subtypes of this product. Once classified, quantities of the same subtype are placed into the central warehouse with other equal subtypes.

Customers place orders at selling points (SPs), while orders to be dispatched and delivered to each SP are prepared in the central warehouse. There are two kinds of SPs (Figure 1); those belonging to own enterprise selling networks (own selling points OSPs); other SPs that belong to the independent selling network (independent selling points - ISPs). These ISPs also commercialise other products from other SCs.

The initial relation of ISPs with the rest of the SC is limited to orders delivery. In order to avoid problems with customers owing to delays or failures in supply, ISPs tend to outsize orders and request an earlier delivery date to that agreed on with the customer. Indeed one usual practice consists in grouping orders, which entails having to deliver 
larger homogeneous quantities than those each customer actually ordered at ISPs. This makes inventory allocation a complex issue because, if the LHP is taken into account, then the larger the amount of homogeneous units required, the more difficult it is to serve the order. These ISPs practices generate reserves of "fictitious" inventory and leave a larger amount of product unavailable for OSPs, which are obliged to delay due dates, which worsens customer service. These practices involve significant drawbacks for the $\mathrm{SC}$ as a whole.

\section{'Insert Figure 1 here'}

In order to improve this situation, greater collaboration of ISPs and the rest of the SC is considered necessary. That is, moving towards a collaborative SC where entities agree on a set of commonly defined objectives, and use their complementary assets to gain long-term competitive advantage (Lejeune and Yakova, 2005). Along these lines, it is worth bearing in mind the determinant role of collaboration and coordination in improving the SC's logistic processes; for instance in Lambert and Cooper (2000), Romano (2003), Holweg and Pil (2008), or in the many works cited in the review by Arshinder et al. (2008).

According to (Akkermans et al., 2004), it is important that SC members share information, basically on current orders, the production status, plans and forecasts. In line with this, the proposed new collaborative framework is based on the ISPs' increased trust in the SC and on the improved information flow which allows the central warehouse to obtain real and accurate knowledge on the orders (quantities and due dates) managed at the ISPs. Within this new collaborative framework, ISPs share information and the central warehouse can centralise decision making about the allocation and reallocation of stocks to orders coming from the OSPs and ISPs, which 
may be considered the maximum degree of collaboration (Alemany et al., 2011) to help achieve the highest level of customer service.

In this way, and if required, with the new DSS proposed, it is possible to use the products reserved by ISPs to cover more urgent orders from OSPs, and vice versa. This has important managerial implications; this new framework of relations based on trust in coordination and collaboration permits ISPs to be completely integrated into the SC as a whole.

The following section describes the mixed integer linear programming model proposed for stock reallocation, which is used by the DSS should there be shortages.

\subsection{Mathematical Programming Model for LHP stock reallocation (SR-LHP)}

This section presents the main characteristics, assumptions and limitations of the LHP stock reallocation problem. Then, the mathematical programming model proposed by the authors to solve it is described. The components of the mathematical programming model are introduced along with the problem presentation to facilitate the later model formulation understanding. The nomenclature used for the SR-LHP-1 model appears in Figure 2.

'Insert Figure 2 here'

As planned production lots are manufactured and received in the central warehouse, they arrive classified into the corresponding subtypes. At this time, checks are made to see if there is a sufficient amount of the uniform subtypes obtained to serve the promised orders. Owing to LHP, it is quite usual that all orders with immediate delivery dates cannot be completely served with the reserved stock because the obtained amount of the different quantities of uniform products differs from those planned, so there is not enough to complete all them. Due to manufacturing lead times, it is not possible to 
obtain new production lots on time in order to complete these orders. An alternative to avoid or minimise delays due to LHP as much as possible consists in reallocating the current inventory of each subtype $(b)$ of each product $(k)$ in the warehouse $\left(q_{k b}\right)$ from orders with no immediate delivery dates to those with immediate delivery dates. When reallocating the LHP current stock and preparing orders for delivery, the following assumptions and limitations should be considered:

- Each customer order $i$ is composed of several order lines $l$. For each order line $l$, the quantity of a specific product $\mathrm{k}$ in order $\mathrm{i}\left(d_{k l i}\right)$ is known. All the lines of the same order have the same due date, implying the time bucket when the customer requests goods to be received. Due to transportation times, the order may have to be delivered before the due date, thus rendering it necessary to differentiate between due dates and delivery dates $\left(f d_{i}\right)$.

- Orders with immediate delivery dates are those with a delivery date $\left(f d_{i}\right)$ lower than the delivery horizon $\left(h_{e}\right)$, i.e., $f d_{i}<=h_{e}$. The delivery horizon $\left(h_{e}\right)$ represents a period length immediately after the current point of time needed to prepare orders to be immediately delivered. This concept helps identify the orders that should be prepared immediately for delivery $\left(I\left(h_{e}\right)\right)$ in order to meet promised customer due dates, and should consequently be completed with the current LHP stock because there is no time to launch new production lots.

- The overall customer orders considered when reallocating the current LHP stock are the committed orders with a delivery date within the delivery horizon $\left(f d_{i}<=h_{e}\right)$, and other orders with some order lines reserved with the current LHP stock with a delivery date within the reallocation horizon $(h)$.

- Partial deliveries are not allowed; that is, all the order lines of an order are jointly served. 
- The requested quantity of a certain product in an order line $\left(d_{k l i}\right)$ should be served through homogeneous units of this product. Hence, each order line is completed with a unique subtype $(b)$ and it is not possible to mix different subtypes to serve an order line in order to guarantee homogeneity.

Given the huge volume of orders, solving the above reallocation problem becomes a very difficult and consuming time task. In this context, mathematical programming models have proven useful tools. In this paper, the authors propose a mixed integer programming model (MILP) to support the decision-making process of reallocating LHP stock to orders with immediate delivery, dubbed SR-LHP-1 (Stock ReallocationLHP-1), as the core of a more sophisticated DSS. The SR-LHP-1 model reallocates available LHP stock among all the input orders by following two objectives: 1) maximise the profits of served orders with the LHP stock; 2) maximise the number of orders served with early delivery dates. The SR-LHP-1 model output provides the decision maker with already committed orders $i$ that must be served from the LHP stock $\left(Y_{i}=1\right)$; for all their order lines $l$, the specific subtype $b$ of product $k$ from the current LHP inventory is used $\left(U_{k l i b}=1\right)$. The SR-LHP-1 model also computes each subtype's remaining current inventory for all the products that has not been reserved by any order after reallocation, thus it becomes available to promise other customer orders $\left(A T P 0_{k b}\right)$. The model formulation proposed to reallocate the current inventory to immediate delivery orders is as follows:

\section{Objective function:}

As previously noted, the objective function includes two objectives. The first objective (1) aims to maximise the total profits obtained from reallocations because only those orders finally reserved with the current LHP stock $\left(Y_{i}=1\right)$ contribute to the total profits. 


$$
\operatorname{Max}\left[z_{1}\right]=\sum_{i} s_{i} \cdot Y_{i}
$$

The second objective (2) attempts to maximise the number of orders reserved from the current inventory with earlier delivery dates, which is the equivalent to maximising the total sum of the difference between the reallocation horizon and the delivery date, because if $h$ is a fixed quantity, then the lower $f d_{i}$, the greater the $h-f d_{i}$ difference. Based on this objective, priority is given to those orders with earlier delivery dates despite their associated profits because it is assumed that for those with later delivery dates, there is more flexibility to find other solutions to serve them (i.e., modifying the master plan with additional production lots). In order to avoid the SR-LHP-1 model not serving those orders with maximum delivery dates $\left(f d_{i}=h\right)$, and as their contribution to the maximisation of $\mathrm{z}_{2}$ is zero $\left(h-f d_{i}=0\right)$, parameter $\varepsilon$ (a positive value lower than the unit) is used to induce the model to serve as many orders as possible. Through parameter $\varepsilon$, the above orders also contribute to the maximisation of $z_{2}$. Therefore, if there is enough LHP stock, the solution first chooses to serve them $\left(Y_{i}=1\right)$.

$$
\operatorname{Max}\left[z_{2}\right]=\sum_{i}\left(h-f d_{i}+\varepsilon\right) \cdot Y_{i}
$$

To avoid allocating current LHP stock to orders with very high associated profits, but also very long delivery dates before other orders with lower associated profits, but with earlier delivery dates, the simultaneous consideration of both objectives is proposed. To that end, they are placed together in a single objective by the complete aggregation procedure, which consists in the sum of the two objectives according to weights $p l$ and $p 2$. These weights are assigned by the decision maker in such a way that the heavier the weight, the greater the importance for the decision maker. As both profits and delivery dates are terms of a very different significance, it is necessary to grade them so that both 
objectives fall within a comparable range which, in this case, is $[0,1]$. Finally, the overall objective function appears as in (3).

$$
\operatorname{Max}[z]=p_{1} \sum_{i}\left(\frac{s_{i}-s_{\min }+\varepsilon}{s_{\max }-s_{\min }}\right) \cdot Y_{i}+p_{2} \sum_{i}\left(\frac{h-f d_{i}+\varepsilon}{h}\right) \cdot Y_{i}
$$

\section{Constraints:}

$$
\begin{array}{lc}
\sum_{i \in I\left(h_{e}\right)} Y_{i}=n_{I\left(h_{e}\right)} & \\
\left(n l_{i}-\sum_{k \in K(i)} \sum_{l \in L(i)} \sum_{b \in B(k)} U_{k l i b}\right) \leq\left(1-Y_{i}\right) \cdot n l_{i} & \forall i \\
U_{k l i b} \leq Y_{i} & \forall i, k \in K(i), l \in L(i, k), b \in B(k) \\
\sum_{i} \sum_{l \in L(i)} d_{k i l} \cdot U_{k l i b}+A T P 0_{k b}=q_{k b} & \forall k, b \in B(k) \\
\sum_{b \in B(k)} U_{k l i b} \leq 1 & \forall i, k \in K(i), l \in L(i, k) \\
U_{k l i b}, Y_{i} \in\{0,1\} & \forall i, k \in K(i), l \in L(i, k), b \in B(k) \\
A T P 0_{k b} \geq 0 & \forall k, b
\end{array}
$$

Constraint (4) forces orders with delivery dates within the delivery horizon to be served. That is, absolute priority is given to reserve the current available LHP stock for these orders.

Constraints (5) ensure that the orders with a number of reserved lines below its number of order lines are not served $\left(Y_{i}=0\right)$. Through these constraints, the orders whose lines have all been allocated can or cannot be served $\left(Y_{i}=0,1\right)$. Therefore, additional constraints (6) are necessary to force orders whose order lines have all been completed with the current LHP inventory to be served $\left(Y_{i}=1\right)$. Only these orders contribute to the objective function. Furthermore, Constraints (6) act in such a way that should an order not be served $\left(Y_{i}=0\right)$, none of its order lines are reserved with the LHP stock. 
Constraints (7) represent balance equations by ensuring that the amount of each subtype $b$ of product $k$ allocated to the different order lines, plus the amount not allocated (uncommitted: $A T P O_{k b}$ ), must equal the amount of that product subtype available in the warehouse. As variable $A T P 0_{k b}$ is non-negative, the allocated LHP stock can never exceed the initial available quantity $\left(q_{k b}\right)$ in the warehouse.

Constraints (8) force each single order line to be completed only with a product subtype. This constraint ensures the required product uniformity in LHP environments, and along with considering several subtypes of each product, it allows LHP characteristics to be properly modelled.

Constraints (9) define decision variables $U_{k l i b}$ and $Y_{i}$ as binary variables.

Finally, Constraints (10) indicate that the remaining current stock of product $k$ and subtype $b$ not allocated to any order is a continuous variable that should be nonnegative $\left(A T P O_{k b}\right)$.

Owing to Constraint (4), the model solution may not be feasible if there is not enough uniform product available in the warehouse to cover all the order requirements with immediate delivery dates. In this case, it is possible to remove Constraint (4) from the model SR-LHP-1 and to solve the resulting model again, dubbed as SR-LHP-2. This new SR-LHP-2 model always provides the decision maker with a feasible solution that also gives priority to orders with earlier delivery dates.

\subsection{DSS architecture}

To facilitate the utilisation of the above models by managers and to provide additional functionalities, a model-driven DSS is proposed (SR-LHP-DSS). In this section, the SRLHP-DSS architecture for the delivery management of LHP SCs is described in accordance with the modules presented in Figure 3 (extraction, pre-processing, solver, post-processing and analysis). 


\section{Extraction:}

The input data for SR-LHP models (parameters, indices and sets) originate from different information systems belonging to the company and the SPs. In the proposed SR-LHP-DSS, information about customer orders is extracted from sales information systems. In the new collaborative framework, the ISPs provide the DSS with the real orders placed by customers (real quantities and due dates) instead of consolidating all the orders, enlarging them and requesting an earlier delivery date. For SCs with LHP is very important to know the exact order size to facilitate the achievement of the homogeneity requirement. Sharing information among collaborative SC members is essential for better decision making. This information includes: the delivery date of each order, the profits obtained and the amount of product requested for each order line. Information about the amounts of products and their subtypes is obtained from the information systems of each production plant and the transport time is obtained from the logistics information system.

'Insert Figure 3 here'

\section{Pre-processing:}

Before running the model, it is necessary to perform previous data processing. This involves calculating the number of order lines in each order $\left(n l_{i}\right)$, the number of orders whose delivery date is within the delivery horizon $\left(n_{I(h e)}\right)$, the delivery date of each order from the central warehouse $\left(f d_{i}\right)$ computed as the difference between the order due date $\left(f e_{i}\right)$ and transport time $\left(t_{s p}\right)$ from the central warehouse to the SP $\left(f d_{i}=f e_{i}-t_{s p}\right)$, the maximum $\left(s_{\max }\right)$ and minimum $\left(s_{\min }\right)$ profit of the orders processed to scale profit and, finally, the total amount of subtypes of products as the sum of the amounts of subtype $(b)$ of products $(k)$ in the production plants $(p): q_{k b}=\sum_{p} q p_{k b p}$. 
Solver:

Before reaching the solving stage, the decision maker should introduce the weights allocated to each objective considered. Firstly, the SR-LHP-1 model is solved: if a solution is obtained, this means that all the orders in the delivery horizon can be served. If an unfeasible solution arises, model SR-LHP-2 is run, which always provides a feasible solution but, in contrast, some orders are not served. The solution obtained includes information about if one order will be completely reserved or not, the subtype of product be reserved for each order line and the amount of the physical stock of each subtype of product be unreserved. The decision maker may confer different values to the weights of each objective and can run the corresponding model several times generating a "what-if" scenario.

\section{Post-processing:}

Post-processing is proposed to provide additional information by comparing the different solutions obtained from modifying the weights allocated to each objective. The SR-LHP-DSS calculates specific performance parameters for each solution (Figure 4), which allow the decision maker to compare them.

\section{'Insert Figure 4 here'}

\section{Analysis:}

The analysis stage must enable the decision maker to consult the results of the model in as much detail as possible for each solution generated. Through this module, the decision maker may analyse how sensitive the solution is to these weights and to compare them with other solutions.

To this end, having executed the model and obtained the performance parameter values, the distance of these parameters to the best value of the performance parameters 
obtained in the solutions to that time is measured and saved from each parameter in the post-treatment stage. This stage involves calculating not only the best value of all the values saved for each parameter until that time (Figure 5), but also deviation in terms of the best values for each solution and for each parameter of the solution (Figure 6).

\author{
'Insert Figure 5 here' \\ 'Insert Figure 6 here'
}

\title{
Decision:
}

As explained, during the stock reallocation process, the information shared among collaborative SC members is used to obtain a solution. Therefore from a collaborative perspective, this aspect facilitates better decision making. However, it is possible to execute the decision process should unforeseen events occur (event-driven); i.e., arrival of urgent orders. Finally, based on the analysis of the results, the decision maker chooses a solution from the existing ones for being implemented.

\section{SR-LHP-DSS validation: case of a ceramic tile supply chain}

The model-driven SR-LHP-DSS is validated by developing a prototype for a real ceramic tile SC. The SR-LHP-DSS results are compared with the manual stock reallocation process carried out by the company. For confidentially reasons, a factor is applied to the overall profits in both cases.

The ceramic tile SC includes three production plants, a central warehouse and 28 SPs, of which 11 are OSP and 17 are ISP. The LHP in the ceramic SC brings about changes in the tone and gage of ceramic tiles. As customers require the same tone and gage in their orders, product subtypes (combination of product-tone-gage) are identified, stored and managed separately in the central warehouse. Besides, orders are prepared in this 
central warehouse to be dispatched and delivered to the SPs (OSP and ISP) where final customers place their orders.

Currently, the ATP policy is First Come - First Committed; i.e., orders are committed as they arrive. Due to this ATP commitment policy and the own LHP effects, the person in charge of deliveries usually needs to reallocate inventories should stock shortage take place to complete orders for immediate delivery. Although the person in charge of managing deliveries has a computer tool that quickly locates product lines for which there is not enough stock (incomplete lines), finding a new solution to complete these lines through the manual reallocation of current stock is very time-consuming, and it is even possible that this solution does not exist.

Data on the manual stock reallocation carried out by the ceramic SC are captured to compare them with the SR-LHP-DSS solutions. The considered reallocation horizon is 1 year. This manual process is performed with 2,274 orders in the planning horizon, with 9,389 lines and an average of 4.12 lines per order, a maximum of 108 lines and a minimum of 1 line per order. The profit made with these orders is $€ 8,648,346.05$. However, there are 934 orders in the order book within the delivery horizon ( 2 weeks) with a total profit of $€ 4,808,518.84$, and the manual reallocation completes 787 of these orders, implying a profit of $€ 3,237,986.38$.

The SR-LHP-DSS helps managers complete those orders with immediate delivered, thus fulfilling order delivery dates in the collaborative SC. The technologies used to construct the SR-LHP- DSS prototype are: Java v7 and the ECLIPSE platform to develop dialog components; MPL 4.2 and the solver CPLEX to translate the mathematical programming models to a readable-machine format; a Microsoft Access database to store the corresponding data. 
The extraction and pre-processing processes are carried out to obtain the input from the ceramic tile information systems in order to provide the SR-LHP models with the same data used in the manual process. Next, the solver is executed to evaluate these data in three solution scenarios generated through different objective function weight definitions (Figure 7).

\section{'Insert Figure 7 here'}

With these input data, the SR-LHP-1 model solution proves unfeasible for the all scenarios because there is not enough homogeneous stock to serve all the order lines in the horizon, so it is not possible to fulfil Constraint [4] of this model. Hence, the SRLHP -2 model is executed and optimal solutions are found. For this second model, the computational time of 4.62 seconds spent to find the optimal solution of W_B case shows the model's utility for real size problems.

The interface design for capturing the performance parameters of the solutions obtained by the SR-LHP DSS for the various scenarios in the post-treatment phase are shown in the following screen (Figure 8). As illustrated in Figure 8, we find: the W_DD scenario, which produces optimal with early delivery dates, completes 1,857 orders with a profit of $€ 5,338,811.74$; the $\mathrm{W} \_\mathrm{B}$ scenario obtains the same number of completed orders, but these orders provide more profit $(€ 5,438,283.74)$; finally, the W_P scenario completes 1,774 orders ( $4.47 \%$ less than the W_DD scenario), but its profit is $€ 5,546,099.32$ (3.88\% more than the W_DD scenario). Thus, the W_P scenario completes fewer orders than the W_DD scenario, but it chooses orders that provide a higher profit. After analysing these findings, as expected, the weights assigned to each objective affect the obtained results, thus validating the proposed SR-LHP models. Furthermore, the possibility for the decision maker to generate multiple solutions by 
changing the objective weights provides a "what-if" scenario, which has proved to be one of the main functionalities for each DSS.

'Insert Figure 8 here'

The decision maker may also be interested in obtaining more details of the results for the delivery horizon because he/she requires an immediate decision (profits, orders completed and uncompleted in $h_{e}$ in Figure 8). The validation allows the comparison of the DSS results obtained by the manual reallocation process carried out in the delivery horizon by the company. Figure 9 offers this comparison using the different objectives weights.

'Insert Figure 9 here'

As observed in Figure 9, manual reallocation completes 787 of the 934 customer orders in the delivery horizon, with a profit of $€ 3,237,986.38$. However, the SR-LHPDSS reallocation obtains more profit than the manual one for all the scenarios. The WDD scenario includes the largest number of completed orders (832), that is $5.72 \%$ more orders than the manual reallocation, as well as $9.32 \%$ more profit than the manual reallocation. The W-B scenario completes fewer orders than the previous scenario (824), but obtains more associated profits ( $10.27 \%$ more than the manual reallocation). The W-P scenario completes the smallest number of orders (766), but makes the most profits (12.06\% more than the manual reallocation). The superiority of the SR-LHPDSS results in all the generated scenarios as compared to the manual reallocation procedure, plus the reduced solution time of the SR-LHP models for real cases, prove the validity of DSS and its convenience in real problems.

Finally, based on the DSS analysis functionality, the decision maker must decide on satisfying more customers (more completed orders) - the solutions have many orders 
not completed - or gaining more benefits not only during the current time period $\left(h_{e}\right)$, but also possibly in the future $(h)$.

\section{Conclusions and future research}

Due to LHP, differences between planned homogeneous quantities and the finally manufactured ones are frequent, which made impossible to serve all promised orders on time with the initial ATP allocation. This paper describes a model-driven DSS to overcome shortage situations during the delivery management of customer orders for collaborative SCs with an MTS strategy characterised by LHP. The DSS core is composed by two novel mathematical programming models with multiple weighted objectives to support LHP-stock reallocations. To facilitate mathematical models utilisation by managers, different functionalities are included in the DSS. Along these lines, and before making a definitive decision, the decision maker can perform different "what-if" simulations (scenarios) by modifying the weight allocated to each objective, and by assessing and comparing different solutions based on diverse performance parameters.

This model-driven DSS has been validated in a collaborative ceramic SC where LHP materialises in the form of different tones and gages in ceramic tiles. The stock reallocations obtained from the DSS in various scenarios have been compared with the ceramic tile company's current procedure. The results demonstrate that the DSS outperforms the manual procedure employed by the ceramic company for all the scenarios generated.

Therefore, the main implications for managers deduced from its use are the following:

1) Considerable time saving in solving the reallocation problem and better quality of solutions obtained; the DSS immediately allows knowing if there is enough 
homogeneous available inventory to deliver all the orders within the delivery horizon and, if so, it provides the optimal solution. When no feasible solution exists, the DSS allows determining the orders to be allocated with the homogeneous inventory to obtain an optimal solution.

2) Support for generating different scenarios and optimal solutions in a user friendly way; by changing the weights of the objectives, the DSS generates as many solutions as the decision maker desires.

3) Support for analysing and comparing the different solutions in order to choose the most satisfactory one.

Furthermore, the DSS also favours the development of a new collaborative context based on greater trust through information sharing and a centralized decisionmaking. In this new context, ISPs no longer transfer information on consolidated orders, which are often inflated, to the central warehouse, but information about their customers' real orders. This information is incorporated into the DSS for supporting the centralized decision making process of reallocating available homogeneous stocks to orders coming from both, the OSPs and ISPs, when shortage situations occurs.

From a practical point of view, the real customers' orders are much smaller than those consolidated by the ISPs that makes easier to find homogeneous units to complete them. Because shortage situations are frequent due to LHP, better reallocation of available stock is made to serve more priority orders. All these aspects will improve SC efficiency by reducing SC inventory holding costs, stocks fragmentation and increasing the customer service level.

Future research lines should consider other objectives derived by applying the SR-LHP-DSS to other sectors. Furthermore, a goal programming model that provides 
the decision maker with non-dominated solutions should be included in the SR-LHPDSS for future implementations. Finally, in order to minimise future stock reallocation due to LHP as much as possible, a knowledge database that collects past patterns of homogeneous quantities in production lots can be designed to predict homogeneous outcomes. This information can be used in production planning to define lot sizes and can be used later during the OP process as a proactive action to LHP.

\section{Acknowledgements}

This research has been carried out within the framework of the project funded by the Spanish Ministry of Economy and Competitiveness (Ref. DPI2011-23597) and the Polytechnic University of Valencia (Ref. PAID-06-11/1840) entitled "Methods and models for operations planning and order management in supply chains characterized by uncertainty in production due to the lack of product uniformity"' (PLANGES-FHP). Also, we thank the comments and suggestions made by the Editors and the Reviewers. In our opinion these changes have improved the quality of the paper.

\section{References}

Abid, C., D'Amours, S. and Montreuil, B., 2004, Collaborative order management in distributed manufacturing. International Journal of Production Research, 42 (2), 283-302.

Akkermans, H., Bogerd, P. and van Doremalen, J., 2004, Travail, transparency and trust: A case study of computer-supported collaborative supply chain planning in high-tech electronics. European Journal of Operational Research, 153 (2), 445456.

Alarcón, F., Alemany, M.M., Lario, F.C. and Oltra, R.F., 2011, La falta de homogeneidad del producto (FHP) en las empresas cerámicas y su impacto en la reasignación de inventario. Boletín de la Sociedad Española de Cerámica y Vidrio, $50(1), 49-58$.

Alarcón, F., Alemany, M.M.E. and Ortiz, A., 2009, Conceptual framework for the characterization of the order promising process in a collaborative selling network context. International Journal of Production Economics, 120 (1), 100-114. 
Alemany, M.M.E., Alarcón, F., Lario, F. and Boj, J.J., 2011, An application to support the temporal and spatial distributed decision-making process in supply chain collaborative planning. Computers in Industry, 62 (5), 519-540.

Alemany, M.M.E., Alarcón, F., Ortiz, A. and Lario, F.C., 2008, Order promising process for extended collaborative selling chain. Production Planning \& Control, 19 (2), 105-131.

Alemany, M.M.E., Lario, F., Ortiz, A. and Gómez, F., 2013, Available-To-Promise modeling for multi-plant manufacturing characterized by lack of homogeneity in the product: An illustration of a ceramic case. Applied Mathematical Modelling, 37 (5), 3380-3398.

Arshinder, Kanda, A. and Deshmukh, S.G., 2008, Supply chain coordination: Perspectives, empirical studies and research directions. International Journal of Production Economics, 115 (2), 316-335.

Azevedo, A.L. and Sousa, J.P., 2000, A component-based approach to support order planning in a distributed manufacturing enterprise. Journal of Materials Processing Technology, 107 (1-3), 431-438.

Balakrishnan, A. and Geunes, J., 2000, Requirements Planning with Substitutions: Exploiting Bill-of-Materials Flexibility in Production Planning. Manufacturing \& Service Operations Management, 2 (2), 166-185.

Bhakoo, V., Singh, P. and Soha, A., 2012, Collaborative management of inventory in Australian hospital supply chains: practices and issues. Supply Chain Management: An International Journal, 17 (2), 217-230.

Bititci, U., Turner, T., Mackay, D., Kearney, D., Parung, J. and Walters, D., 2007, Managing synergy in collaborative enterprises. Production Planning \& Control, 18 (6), 454-465.

Boza, A., Ortiz, A., Cuenca, L., 2010, A framework for Developing a Web-Based Optimization Decision Support System for Intra/Inter-Organizational DecisionMaking Processes. Balanced Automation Systems for Future Manufacturing Networks, 322, 121-128

Framiñán, J.M. and Leisten, R., 2009, Available-to-promise (ATP) systems: a classification and framework for analysis. International Journal of Production Research, 48 (11), 3079-3103.

Gomes da Silva, C., Figueira, J., Lisboa, J. and Barman, S., 2006, An interactive decision support system for an aggregate production planning model based on multiple criteria mixed integer linear programming. Omega, 34 (2), 167-177.

Hernandez, J.E., Poler, R., Mula, J., Lario, F.C., 2011, The reverse logistic process of an automobile supply chain network supported by a collaborative decision-making model. Group Decision and Negotiation, 20 (1), 79-114. 
Holweg, M. and Pil, F.K., 2008, Theoretical perspectives on the coordination of supply chains. Journal of Operations Management, 26 (3), 389-406.

Jagdev, H.S. and Thoben, K.D., 2001, Anatomy of enterprise collaborations. Production Planning \& Control, 12 (5), 437-451.

Kubat, C., Öztemel, E. and Taşkın, H., 2007, Decision support systems in production planning and control. Production Planning \& Control, 18 (1), 1-2.

Lambert, D.M. and Cooper, M.C., 2000, Issues in Supply Chain Management. Industrial Marketing Management, 29, 65-83.

Lejeune, M.A. and Yakova, N., 2005, On characterizing the 4 C's in supply chain management. Journal of Operations Management, 23 (1), 81-100.

Okongwu, U., Lauras, M., Dupont, L. and Humez, V., 2012, A decision support system for optimising the order fulfilment process. Production Planning \& Control, 23 (8), 581-598.

Pibernik, R., 2006, Managing stock-outs effectively with order fulfilment systems. Journal of Manufacturing Technology Management, 17 (6), 721-736.

Poler, R., Hernández, J.E., Mula, J. and Lario, F.C., 2008, Collaborative forecasting in networked manufacturing enterprises. Journal of Manufacturing Technology Management, 19 (4), 514-528.

Romano, P., 2003, Co-ordination and integration mechanisms to manage logistics processes across supply networks. Journal of Purchasing and Supply Management, 9, 119-134.

Zschorn, L., 2006, An extended model of ATP to increase flexibility of delivery. International Journal of Computer Integrated Manufacturing, 19 (5), 434-442. 


\section{Figure 1. The Physical SC Configuration and the DSS Collaboration Framework}

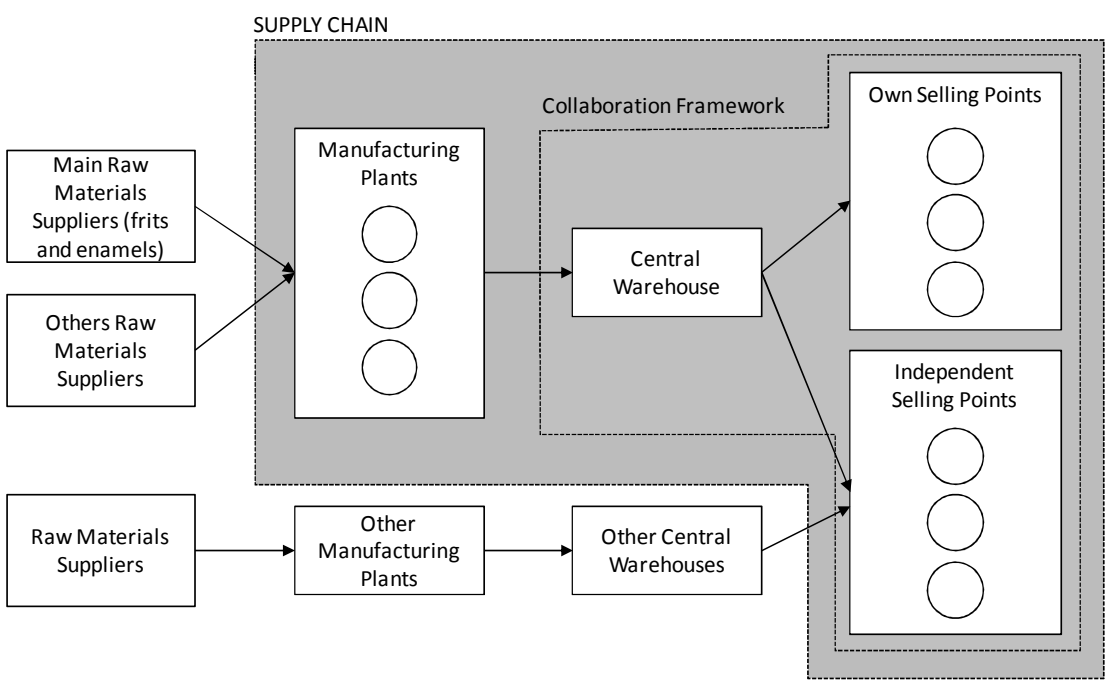

Figure 2. Nomenclature

\begin{tabular}{|c|c|c|}
\hline \multicolumn{2}{|r|}{ Indices } & Sets \\
\hline & $\begin{array}{l}\text { each order with a delivery date within the horizon } \\
(\mathrm{i}=1 \ldots \mathrm{I})\end{array}$ & $\begin{array}{ll}I\left(h_{e}\right) & \text { the set of orders whose delivery date is } \\
\text { within the delivery horizon }\end{array}$ \\
\hline & $\begin{array}{l}\text { each order line that makes up the orders being } \\
\text { considered }(1=1 \ldots \mathrm{L})\end{array}$ & $\begin{array}{l}L(i, k) \text { the set of order lines } 1 \text {, which contain product } \\
\mathrm{k} \text { and correspond to order } i \text {. }\end{array}$ \\
\hline & each existing product in considered orders $(\mathrm{k}=1 \ldots \mathrm{K})$ & the set of existing subtypes of product $k$ \\
\hline & $\begin{array}{l}\text { each existing product subtype in considered products } \\
(\mathrm{b}=1 \ldots \mathrm{B})\end{array}$ & $\begin{array}{l}K(i) \text { the set of products } \mathrm{k} \text { which are included in } \\
\text { order } i\end{array}$ \\
\hline \multicolumn{3}{|c|}{ Parameters } \\
\hline$p_{1}$ & \multicolumn{2}{|c|}{ A specific weight that the decision-maker confers to the profit in the objective function } \\
\hline$p_{2}$ & \multicolumn{2}{|c|}{$\begin{array}{l}\text { A specific weight that the decision maker confers in order to serve orders with earlier delivery dates in the } \\
\text { objective function }\end{array}$} \\
\hline$s_{i}$ & \multicolumn{2}{|l|}{ Profits from order $i$} \\
\hline$h$ & \multicolumn{2}{|c|}{$\begin{array}{l}\text { Reallocation horizon. This is the delivery deadline date which determines the orders to be considered by the } \\
\text { model; orders whose delivery dates are equal to or before the horizon }\end{array}$} \\
\hline$h_{e}$ & \multicolumn{2}{|c|}{$\begin{array}{l}\text { Orders delivery horizon. This date determines which orders should be prepared in the warehouse to be } \\
\text { subsequently dispatched and delivered to the customer: orders whose dispatch dates are equal to or before } \\
\text { the delivery horizon }\end{array}$} \\
\hline$f d_{i}$ & \multicolumn{2}{|l|}{ Dispatch date of order $i$ from the central warehouse } \\
\hline & \multicolumn{2}{|c|}{ Number of orders whose dispatch date are within the delivery horizon $\left(h_{e}\right)$. } \\
\hline$n l_{i}$ & \multicolumn{2}{|l|}{ Number of order lines that order $i$ has } \\
\hline$d_{k l i}$ & \multicolumn{2}{|l|}{ The ordered amount of product $k$, in line $l$ of order $i$} \\
\hline$q_{k b}$ & \multicolumn{2}{|c|}{ The amount of product $k$ and subtype $b$ available in the warehouse } \\
\hline$s_{\max }$ & \multicolumn{2}{|l|}{ Maximum of $S_{i}$. } \\
\hline$s_{\min }$ & \multicolumn{2}{|l|}{ Minimum of $s_{i}$. } \\
\hline & \multicolumn{2}{|l|}{ A positive and lower value than the unit } \\
\hline \multicolumn{3}{|c|}{ Decision variables } \\
\hline$Y_{i}$ & \multicolumn{2}{|c|}{$\begin{array}{l}\text { Binary variable that takes a value of } 1 \text { if order } i \text { is completely reserved (all its } L(i) \text { lines are reserved with } \\
\text { the real inventory), and a value of } 0 \text { otherwise }\end{array}$} \\
\hline$U_{k l i b}$ & \multicolumn{2}{|c|}{$\begin{array}{l}\text { Binary variable that takes a value of } 1 \text { if line } l \text { of order } i \text { has a current inventory reserve of product } k \text { and } \\
\text { subtype } b \text { and a value of } 0 \text { otherwise }\end{array}$} \\
\hline \multicolumn{3}{|c|}{$\begin{array}{l}A T P O_{k b} \text { The real inventory amount of product } k \text { and subtype } b \text {, which is not reserved after having reassigned the } \\
\text { current inventory and, therefore, it remains available to compromise with other orders. }\end{array}$} \\
\hline
\end{tabular}


Figure 3. The SR-LHP-DSS architecture

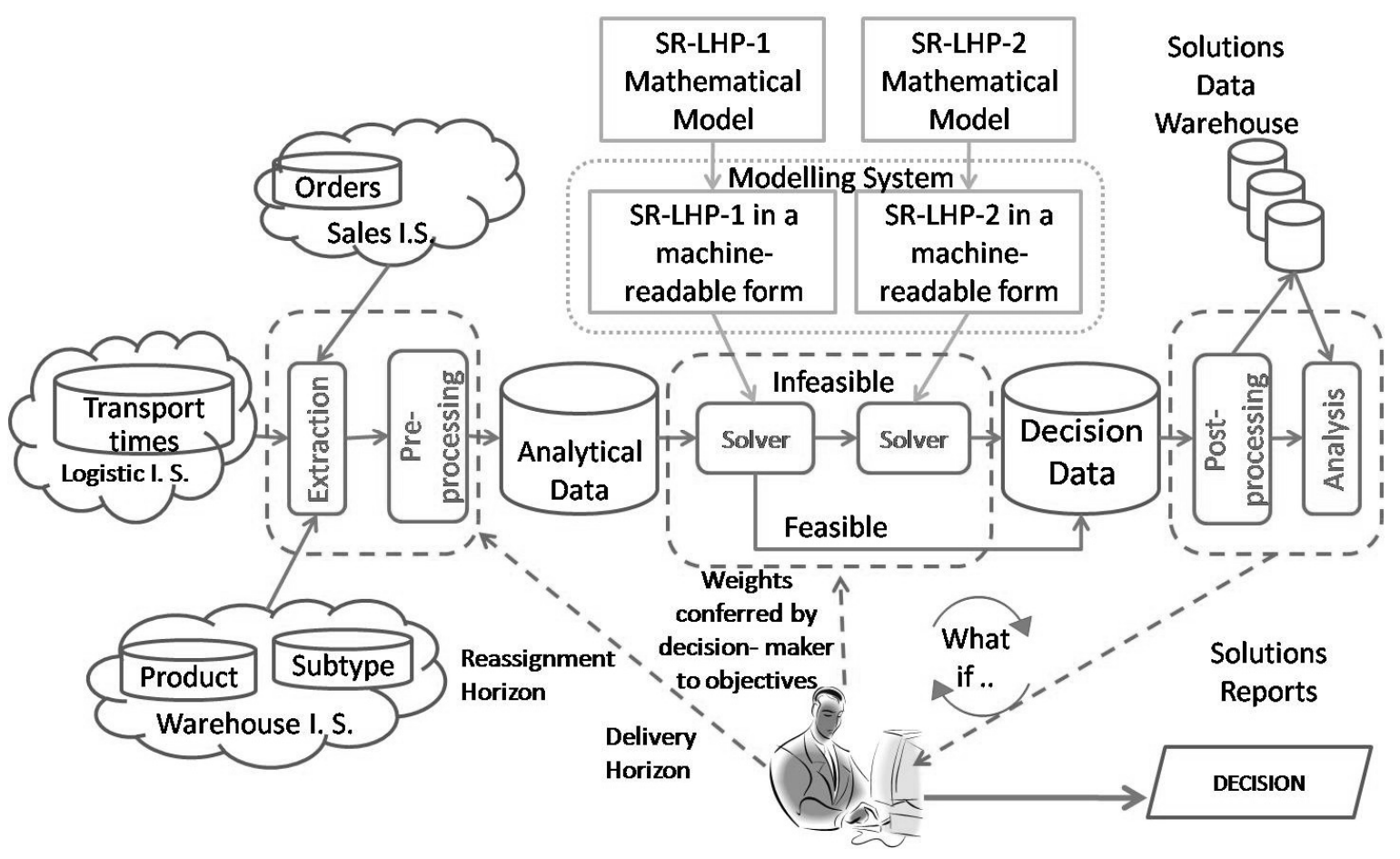

Figure 4. The parameters obtained with the post-treatment 


\begin{tabular}{|c|c|c|c|}
\hline $\mathrm{z}(\mathrm{j})$ & $\begin{array}{l}\text { Objective function value in } \\
\text { solution " } \mathrm{j} \text { ". }\end{array}$ & $\begin{array}{l}\mathrm{SO}(\mathrm{j})= \\
\sum_{i} Y_{i}(j)\end{array}$ & $\begin{array}{l}\text { Number of orders } \\
\text { completed in } \\
\text { reallocation horizon } \\
\text { (h) in solution "j". } \\
\end{array}$ \\
\hline $\mathrm{p} 1(\mathrm{j})$ & $\begin{array}{l}\text { Weight conferred by the } \\
\text { decision maker to the } \\
\text { profits in the objective } \\
\text { function in solution " } \mathrm{j} \text { ". }\end{array}$ & $\begin{array}{l}\mathrm{NSO}(\mathrm{j})= \\
\mathrm{I}-\sum_{i} Y_{i}(j)\end{array}$ & $\begin{array}{l}\text { Number of orders to } \\
\text { still be completed in } \\
\text { reallocation horizon } \\
\text { (h) in solution "j". }\end{array}$ \\
\hline $\mathrm{p} 2(\mathrm{j})$ & $\begin{array}{l}\text { Weight conferred by the } \\
\text { decision maker to serve } \\
\text { orders with an earlier } \\
\text { dispatch date in the } \\
\text { objective function in } \\
\text { solution " } \mathrm{j} \text { ". }\end{array}$ & $\begin{array}{l}\mathrm{SO}_{\text {he }}(\mathrm{j})= \\
\qquad \sum_{i \in l\left(h_{i:}\right)} y_{t}(j)\end{array}$ & $\begin{array}{l}\text { Number of orders } \\
\text { completed in the } \\
\text { delivery horizon }\left(h_{e}\right) \\
\text { in solution "j". }\end{array}$ \\
\hline zl(j) & $\begin{array}{l}\text { The objective function } \\
\text { value in relation to the } \\
\text { profits of completed orders } \\
\text { in reallocation horizon (h) } \\
\text { in solution "j". }\end{array}$ & $\begin{array}{l}\mathrm{NSO}_{\text {he }}(\mathrm{j})= \\
I-\sum_{i \in T\left(h_{e}\right)} Y_{t}(j)\end{array}$ & $\begin{array}{l}\text { Number of orders to } \\
\text { still be completed in } \\
\text { the delivery horizon } \\
\left(h_{e}\right) \text { in solution "j". }\end{array}$ \\
\hline $\mathrm{z} 1_{\mathrm{he}}(\mathrm{j})$ & $\begin{array}{l}\text { The objective function } \\
\text { value in relation to the } \\
\text { profits of completed orders } \\
\text { in delivery horizon }\left(\mathrm{h}_{\mathrm{e}}\right) \text { in } \\
\text { solution " } \mathrm{j} \text { ". }\end{array}$ & $\begin{array}{l}\operatorname{ATP} 0 \max (\mathrm{j})_{\mathrm{k}}= \\
\underset{b}{\operatorname{Max}}\left(\operatorname{ATP} 0(j)_{k b}\right)\end{array}$ & $\begin{array}{l}\text { Maximum amount not } \\
\text { assigned from the real } \\
\text { inventory for product } \\
\mathrm{k} \text { in solution "j". }\end{array}$ \\
\hline z2(j) & $\begin{array}{l}\text { The objective function } \\
\text { value in relation to the } \\
\text { delivery dates in } \\
\text { reallocation horizon (h) in } \\
\text { solution " } \mathrm{j} \text { ". }\end{array}$ & $\begin{array}{l}\mathrm{ATP} 0 \min (\mathrm{j})_{\mathrm{k}}= \\
\operatorname{Min}\left(A T P 0(j)_{k b}\right)\end{array}$ & $\begin{array}{l}\text { Minimum size of that } \\
\text { which has not been } \\
\text { assigned from the real } \\
\text { inventory for product } \\
\mathrm{k} \text { in solution "j". }\end{array}$ \\
\hline $\mathrm{z} 2_{\mathrm{he}}(\mathrm{j})$ & $\begin{array}{l}\text { The objective function } \\
\text { value in relation to the } \\
\text { delivery dates in delivery } \\
\text { horizon }\left(\mathrm{h}_{\mathrm{e}}\right) \text { in solution " } \mathrm{j} \text { ". }\end{array}$ & $\begin{array}{l}\text { ATP0med }(\mathrm{j})_{\mathrm{k}}= \\
\sum_{b}\left(\frac{A T P 0(j) k b}{|B(k)|}\right)\end{array}$ & $\begin{array}{l}\text { Average size of that } \\
\text { which has not been } \\
\text { assigned from the } \\
\text { current inventory for } \\
\text { product k in solution } \\
\text { "j". }\end{array}$ \\
\hline
\end{tabular}

Figure 5. Calculation of the best values of each parameter in the post-treatment of all the saved solutions $\mathrm{j}$. 


\begin{tabular}{|c|c|}
\hline$Z \max =\operatorname{Max}_{j}[z(j)]$ & $\begin{array}{l}\text { Maximum value of the objective function of } \\
\text { all the saved solutions } j\end{array}$ \\
\hline $\mathrm{z} 1 \max =\underset{j}{\operatorname{Max}}[z 1(j)]$ & $\begin{array}{l}\text { Maximum value of the objective related to } \\
\text { the profits of all the saved solutions } \mathrm{j} \text { in the } \\
\text { reallocation horizon (h) }\end{array}$ \\
\hline $\mathrm{z} 2 \max =\underset{j}{\operatorname{Max}}[z 2(j)]$ & $\begin{array}{l}\text { Maximum value of the objective related to } \\
\text { the delivery date of all the saved solutions } \mathrm{j} \\
\text { in the reallocation horizon }(\mathrm{h})\end{array}$ \\
\hline $\mathrm{z}_{\mathrm{he}} \max =\operatorname{Max}_{j}\left[z 1_{\mathrm{he}}(j)\right]$ & $\begin{array}{l}\text { Maximum value of the objective related to } \\
\text { the profits of all the saved solutions } j \text { in the } \\
\text { delivery horizon }\left(h_{e}\right)\end{array}$ \\
\hline $\mathrm{z} 2_{\mathrm{he}} \max =\underset{j}{\operatorname{Max}\left[z 2_{\mathrm{he}}(j)\right]}$ & $\begin{array}{l}\text { Maximum value of the objective related to } \\
\text { the delivery date of all the saved solutions } \mathrm{j} \\
\text { in the delivery horizon }\left(\mathrm{h}_{\mathrm{e}}\right)\end{array}$ \\
\hline$S O \max =\operatorname{Max}_{j}[S O(j)]$ & $\begin{array}{l}\text { Maximum number of orders served of all the } \\
\text { saved solutions } j \text { in the reallocation horizon } \\
\text { (h) }\end{array}$ \\
\hline$N S O \min =\operatorname{Min}_{j}[N S O(j)]$ & $\begin{array}{l}\text { Minimum number of orders to be served of } \\
\text { all the saved solutions } j \text { in the reallocation } \\
\text { horizon (h) }\end{array}$ \\
\hline 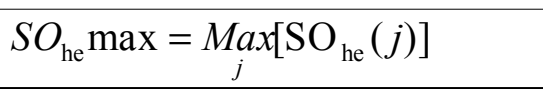 & $\begin{array}{l}\text { Maximum number of orders served of all the } \\
\text { saved solutions } j \text { in the delivery horizon }\left(h_{e}\right)\end{array}$ \\
\hline$N S O_{\mathrm{he}} \min =\operatorname{Min}_{j}\left[N S \mathrm{~S}_{\mathrm{he}}(j)\right]$ & $\begin{array}{l}\text { Minimum number of orders to be served of } \\
\text { all the saved solutions } j \text { in the delivery } \\
\text { horizon }\left(h_{e}\right)\end{array}$ \\
\hline$\overline{\operatorname{ATP} 0 \max }_{k}=\operatorname{Max}_{j}\left[A T P 0 \max (j)_{k}\right]$ & $\begin{array}{l}\text { The largest size of the maximum remaining } \\
\text { stock of product } k \text { of all the saved solutions } j\end{array}$ \\
\hline$\overline{\operatorname{ATP0\operatorname {min}}}_{k}=\operatorname{Min}\left[A T P 0 \min (j)_{k}\right]$ & $\begin{array}{l}\text { The smallest size of the minimum remaining } \\
\text { stock of product } k \text { of all the saved solutions } j\end{array}$ \\
\hline$\overline{\operatorname{ATP0med}}_{k}=\sum_{j} A T P 0 \operatorname{med}(j)_{k} /|j|$ & $\begin{array}{l}\text { The average size of the average remaining } \\
\text { stock of each product } k \text { obtained with all the } \\
\text { saved solutions } j\end{array}$ \\
\hline
\end{tabular}


Figure 6. Calculation of the deviations for each parameter and solution in relation to the best values of each parameter in the post-treatment.

\begin{tabular}{|c|c|}
\hline$\Delta z(j)=Z \max -z(j)$ & $\begin{array}{l}\text { Deviation of solution ( } \mathrm{j} \text { ) in relation to the } \\
\text { best value of the objective function of all } \\
\text { the solutions considered in the reallocation } \\
\text { horizon (h) }\end{array}$ \\
\hline$\Delta z 1(j)=z 1 \max -z 1(j)$ & $\begin{array}{l}\text { Deviation of solution ( } \mathrm{j} \text { ) in relation to the } \\
\text { best value of the objective related to the } \\
\text { profits of all the solutions considered in } \\
\text { the reallocation horizon (h) }\end{array}$ \\
\hline$\Delta z 2(j)=z 2 \max -z 2(j)$ & $\begin{array}{l}\text { Deviation of solution (j) in relation to the } \\
\text { best value of the objective related to the } \\
\text { delivery date of all the solutions } \\
\text { considered in the reallocation horizon (h) }\end{array}$ \\
\hline$\Delta \mathrm{z} 1(j)=z 1_{\mathrm{he}} \max -z 1_{\mathrm{he}}(j)$ & $\begin{array}{l}\text { Deviation of solution }(j) \text { in relation to the } \\
\text { best value of the objective related to the } \\
\text { profits of all the solutions considered in } \\
\text { the delivery horizon }\left(\mathrm{h}_{\mathrm{e}}\right)\end{array}$ \\
\hline$\Delta \mathrm{z} 2(j)=z 2_{\mathrm{he}} \max -z 2_{\mathrm{he}}(j)$ & $\begin{array}{l}\text { Deviation of solution }(\mathrm{j}) \text { in relation to the } \\
\text { best value of the objective related to the } \\
\text { delivery date of all the solutions } \\
\text { considered in the delivery horizon }\left(\mathrm{h}_{\mathrm{e}}\right)\end{array}$ \\
\hline$\Delta S O(j)=S O \max -S O(j)$ & $\begin{array}{l}\text { Deviation of solution ( } \mathrm{j} \text { ) in relation to the } \\
\text { maximum number of orders served of all } \\
\text { the solutions considered in the reallocation } \\
\text { horizon (h) }\end{array}$ \\
\hline$\Delta N S O(j)=N S O(j)-N S O$ min & $\begin{array}{l}\text { Deviation of solution ( } \mathrm{j} \text { ) in relation to the } \\
\text { minimum number of orders to be served of } \\
\text { all the solutions considered in the } \\
\text { reallocation horizon }(\mathrm{h})\end{array}$ \\
\hline$\Delta \mathrm{SO}_{\mathrm{he}}(j)=S O_{\mathrm{he}} \max -S O_{\mathrm{he}}(j)$ & $\begin{array}{l}\text { Deviation of solution }(\mathrm{j}) \text { in relation to the } \\
\text { maximum number of orders served of all } \\
\text { the solutions considered in the delivery } \\
\text { horizon }\left(\mathrm{h}_{\mathrm{e}}\right)\end{array}$ \\
\hline$\Delta N S O_{\text {he }}(j)=N S O_{\text {he }}(j)-N S O_{\text {he }} \min$ & $\begin{array}{l}\text { Deviation of solution }(\mathrm{j}) \text { in relation to the } \\
\text { minimum number of orders to be served of } \\
\text { all the solutions considered in the delivery } \\
\text { horizon }\left(\mathrm{h}_{\mathrm{e}}\right)\end{array}$ \\
\hline $\begin{array}{l}\Delta{\overline{A T P 0 \max (j)_{k}}}_{k}= \\
\overline{A T P 0 \max }_{k}-A T P 0 \max (j)_{k}\end{array}$ & $\begin{array}{l}\text { Deviation of solution }(j) \text { in relation to the } \\
\text { maximum size of the remaining stock for } \\
\text { product } k \text { of all the solutions considered }\end{array}$ \\
\hline $\begin{array}{l}\Delta \overline{A T P 0 \min (j)}_{k}= \\
{\overline{\operatorname{ATP} 0 \min _{k}}}-A T P 0 \min (j)_{k}\end{array}$ & $\begin{array}{l}\text { Deviation of solution }(j) \text { in relation to the } \\
\text { minimum size of the remaining stock of } \\
\text { product } k \text { of all the solutions considered }\end{array}$ \\
\hline 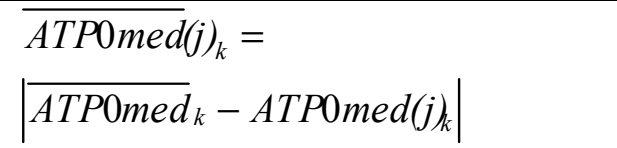 & $\begin{array}{l}\text { Deviation of solution }(j) \text { in relation to the } \\
\text { average size of the remaining stock of } \\
\text { product } k \text { of all the solutions considered }\end{array}$ \\
\hline
\end{tabular}

Figure 7: Scenarios definition for the SR-LHP DSS 


\begin{tabular}{|ll|c|c|}
\hline \multirow{2}{*}{ Solution Name } & \multicolumn{2}{|c|}{ Weights } \\
\cline { 3 - 4 } & Profits (p1) & Delivery Date (p2) \\
\hline (W-DD) & Weight in delivery dates & 0 & 1 \\
\hline (W-B) & Weights balanced & 0.5 & 0.5 \\
\hline (W-P) & Weight in profits & 1 & 0 \\
\hline
\end{tabular}

Figure 8 . The performance parameter values for W_DD, W_B and W_P.

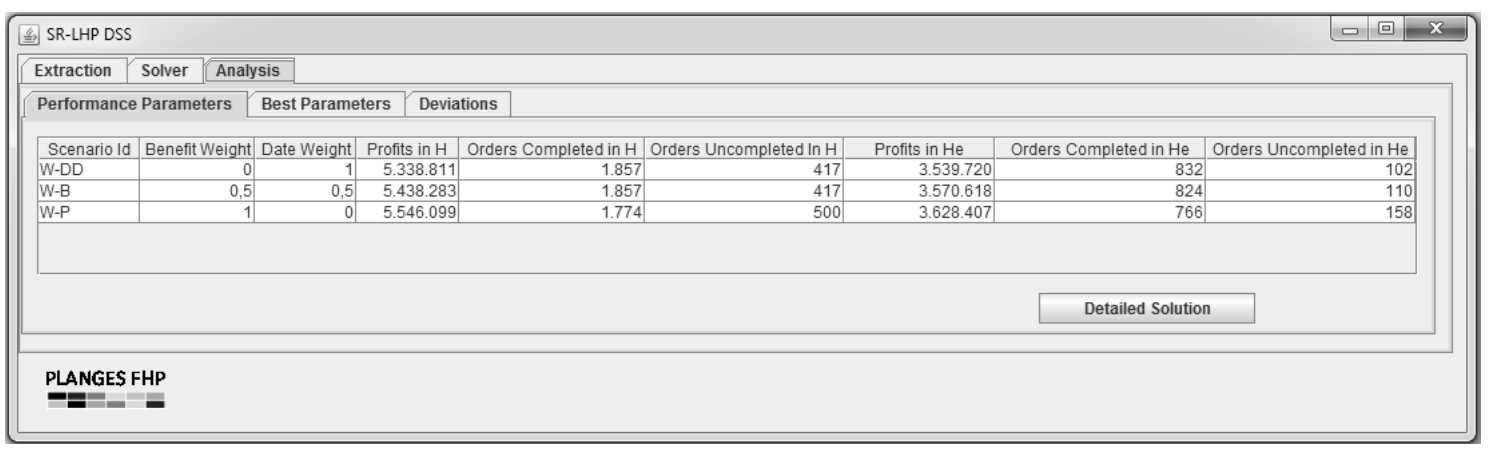

Figure 9. The manual and SR-LHP-DSS reallocations inside $h_{e}$.

\begin{tabular}{|c|c|c|c|c|c|}
\hline & & $\begin{array}{c}\text { Orders } \\
\text { Completed } \\
\text { inside } h_{e} \\
\end{array}$ & $\begin{array}{l}\text { Manual \& DSS } \\
\text { Difference }\end{array}$ & Profits & $\begin{array}{c}\text { Manual \& DSS } \\
\text { Difference }\end{array}$ \\
\hline Company & Manual & 787 & --- & $3,237,986.38 €$ & --- \\
\hline DSS Scenarios & $\begin{array}{c}\text { W_DD } \\
\text { W_B } \\
\text { W_P }\end{array}$ & $\begin{array}{l}832 \\
824 \\
766\end{array}$ & $\begin{array}{c}5.72 \% \\
4.7 \% \\
-2.67 \%\end{array}$ & $\begin{array}{l}3,539,720.29 € \\
3,570,618.21 € \\
3,628,407.22 €\end{array}$ & $\begin{array}{c}9.32 \% \\
10.27 \% \\
12.06 \%\end{array}$ \\
\hline
\end{tabular}

